\title{
Smoking Cessation and Attitudes, Belief, Observation, and Education of Medical Students, in Turkey
}

\author{
Ebru Turhan, ${ }^{1}$ Tacettin Inandi, ${ }^{2}$ Meltem Col, ${ }^{3}$ Resul Bugdayci, ${ }^{4}$ Olga Eker, ${ }^{5}$ Mustafa Ilhan ${ }^{6}$ \\ ${ }^{1}$ Izmir Public Health Directorate, IZMIR, Turkey, ${ }^{2}$ Mustafa Kemal University, Faculty of Medicine, Department of Public \\ Health, Antakya, Hatay, Turkey, ${ }^{3}$ Ankara University, Faculty of Medicine, Department of Public Health, Ankara, Turkey, ${ }^{4}$ \\ Mersin University, Faculty of Medicine, Department of Public Health, Mersin, Turkey, ${ }^{5}$ Seyhan Community Health Center, \\ Adana, Turkey, ${ }^{6}$ Gazi University, Faculty of Medicine, Department of Public Health, Ankara, Turkey.
}

\section{ABSTRACT}

Introduction: Tobacco use is an important public health problem around the world. Aim of this study is to assess attitudes, belief and observation of the students on smoking cessation and medical education.

Methods: This study is part of a multi-country study called "Global Health Profession Student Survey". The study population consisted of third year medical students in Turkey. The sample consisted of a total of 1834 medical students from randomly selected 12 medical schools.

Results: Of the students, 1209 (92.1\%)thought that health professionals should get specific training on cessation techniques, and that health professionals should serve as "role models" for their patients and the public. The percentage of the students who answered "Health professionals should routinely advise their patients who smoke to quit smoking" was 1211 (93.3\%). Of the students, 1204 (60.8\%) responded that health professionals who use other tobacco products were less likely to advise patients to stop smoking. The percentage of the students who had received a formal training on smoking cessation approaches was $48.2 \%$ (1196). Of the students, $91.5 \%$ (1203) had heard of nicotine replacement therapies in tobacco cessation programs. More than half of smokers tried to quit smoking last year, and majority of them did not take professional help or advice.

Conclusions: Majority of students are aware of health professionals' role on smoking cessation. Most of the students are willingness to take specific formal training on tobacco. Student's behaviours and attitudes were different by gender and smoking status. Improvement of tobacco cessation issues in medical curricula will be beneficial.

Keywords: attitudes; beliefs; medical education; medical students; smoking cessation.

\section{INTRODUCTION}

Tobacco use is an important public health problem around the world. It kills more than 5 million people per year, and killed 100 million people worldwide in the 20th century. ${ }^{1}$ Regarding to tobacco consumption, Turkey is the third country among the European countries, ${ }^{2}$ and
$31.2 \%$ of adults aged 15 years and older were smoker in $2010 .^{3}$

Smoking prevalence among medical students was

Correspondence: Dr. Ebru Turhan, Public Health, Provincial Directorate of Public Health, Research and Development Unit, Karsiyaka, IZMIR, Turkey. Email: turhanebru1@gmail.com, Phone: 05055602768. 
between 23-42 \%.4-6 Smoking prevalence was found to be $30.5 \%$ in general practitioners and $22.1 \%$ in specialists, in 2008. ${ }^{7}$ Physicians' attitudes and behaviours are clearly important for health education of public. ${ }^{8}$ Physicians' questioning about smoking status and advice to quit smoking has a significant positive effect on cessation. Health professionals have to play an active role in improving the health of the population. ${ }^{9}$

Aim of this study is to assess beliefs, attitudes, and observation of the students on counselling, smoking cessation, role of the health professional and medical education.

\section{METHODS}

Study Design: "Global Health Profession Student Survey" (GHPSS) has a standardized methodology for selecting participating schools and classes and uniform data processing procedures. GHPSS is a school-based survey of third-year students pursuing advanced degrees in dentistry, medicine, nursing and pharmacy. ${ }^{10}$

Place and duration of study: The study population consisted of third year medical students in Turkey in 2008. There were 66 medical faculties, and 51 schools of them had students in the academic year of 20062007.

Ethical approval and informed consent: The informed and verbal consent was received from the students, being informed about the topic and the objective of the study. In the data-collecting stage, the practices performed were in compliance with the rules contained within The Declaration of Helsinki. However, we did not request ethical committee approval.

Study Sample:The study population consisted of third year medical students in Turkey in 2008. There were 66 medical faculties, and 51 of them had students in the academic year of 2006-2007. The total enrolment was 4980 . The sample size was calculated according to GHPSS Survey Administrator Handbook 2009. ${ }^{10}$ The study sample consisted of a total of 1834 medical students from randomly selected 12 medical schools. However 672 students were excluded after fulfilment of the questionnaire because they were not in the third year in their schools. Students; $86.4 \%$ of the 2,186 sampled students completed the questionnaires. After the exclusions, 1217 students were analysed.

Data Collection Procedures and Statistical Analysis: GHPSS is composed of a core questionnaire designed to gather data on five topics related to prevalence of tobacco use, exposure to second-hand smoke, training and knowledge about the health effects of tobacco use, attitudes about tobacco and cessation of tobacco use. Among these topics the one entitled with role model and cessation training are evaluated in this paper. An invitation letter was sent to the deans of the selected schools and survey administrators from public health departments of each selected school were recruited for data collection Survey procedures were designed to protect the students' privacy by allowing for anonymous and voluntary participation. The self-administered questionnaire was administered in classrooms.

All analysis used weighted data. Version 7 of Epi Info ${ }^{\mathrm{TM}}$ was used to analyze data. Statistical differences were determined by comparing $95 \%$ Confidence Intervals (Cl). If the $\mathrm{Cl}$ did not overlap then differences were significant at the $p<0.5$ level.

"Ever user" was defined as "having used tobacco even once in their lifetime'. "Current use" was defined as 'having used tobacco at least once in the last 30 days preceding the survey". "Never use" was defined as 'having not used tobacco even once in their lifetime'.

\section{RESULTS}

Most of the students were in the age group of 19 to 24, and 632 (55.3\%) were female. Lifetime prevalence was $828(68.0 \%)$ accounting for $386(76.5 \%)$ in the males and $442(61.1 \%)$ in the females. The current prevalence was 351 (28.5\%) accounting for 119 $(40.2 \%)$ in the males and $232(18.9 \%)$ in the females.

Smoking cessation behaviours were presented in (Table 1). Nearly half of current cigarette smokers reported to have desire for a cigarette within one hour of awakening in morning, indicating strong dependence on tobacco. Although 151 (56.2\%) of the current cigarette smokers stated that they wanted to stop smoking, this percentage was $45(30.8 \%)$ among other tobacco users. Of current cigarette smokers, 174 (60.4\%) tried to stop smoking the past year. Among ever smokers, 1009 (83.6\%) reported to have never received help/ advice to stop smoking.

Opinions on specific training by gender and smoking status were presented in (Table 2); 1115 (92.1\%) of the students thought that health professionals should get specific training on cessation techniques.

With regard to smoking status and specific training, the lowest percentage was in current smokers with 231 $(81.3 \%)$, and the highest was in the never user of any tobacco product with 378 (95.4\%).

Opinions of the students on role models were presented in (Table 3); 1209 (92.1\%) said that health professionals should serve as "role models" for their patients and 
public. The lowest percentage was in the current cigarette smokers while the highest was in the never any tobacco users. Of the students, 1211 (93.3\%) thought that health professionals should routinely advise their patients who smoke to quit smoking.

To the question "Should health professionals routinely advise their patients who use other tobacco products to quit using these products?" 1207 (92.6\%) said 'Yes'. There was a significant difference between all type of tobacco users and never users.

Of the students, 1209 (94.4\%) agreed that health professionals have a role in giving advice or information about smoking cessation to their patients. The highest percentage of "Yes" answers was in the never cigarette smokers while the lowest was in the current cigarette smokers.

"Are a patient's chances of quitting smoking increased if a health professional advises him or her to quit?", $1203(89.9 \%)$ of the responses were "Yes", and the differences by smoking status were not significant.

"Are health professionals who smoke less likely to advise patients to stop smoking?" 1204 (60.8\%) of responses were "Yes" answers. The current smokers had the lowest percentage of "Yes" while never any tobacco users had the highest.

Of the students, $1203(60.8 \%)$ responded that health professionals who use other tobacco products were less likely to advise patients to stop smoking. The differences between current other tobacco users and never users were significant. Questions and responses about medical curriculum/trainings and smoking were presented in (Table 4); 87.2\% (1195) of the students said that they were taught in any of their classes about the harmful effects of tobacco.

Of the 1205 students, $50.4 \%$ (607) responded that they discussed the reasons why people smoke, in any of their classes. Among the 1200 students, 90.8\% (1090) said that they learned to record tobacco use history as part of a patient's general medical history taking. Of the students, $48.2 \%$ (1196) had received a formal training on smoking cessation approaches to use with patients. Of the 1202 students, $61.2 \%$ (736) had learned that it was important to provide educational materials support to patients who want to quit smoking.

Of the students, $91.5 \%$ (1203) had heard of nicotine replacement product therapies in tobacco cessation programs, and the differences were not significant. With regard to other drug therapies, $45.7 \%$ (1204) had heard of using antidepressants in tobacco cessation programs, and $30.8 \%$ (1202) had heard of using varenicline in tobacco cessation programs.

\section{DISCUSSION}

Health professionals are considered role models by people at large. In this context, reducing tobacco use among physicians may be one of the best effective strategies. Therefore, in addition to medical school facilities, education and tobacco policies, students' attitudes and behaviours are the key elements. We think that we should focus on these issues in order to reduce tobacco use among the physicians.

More than half of the current smokers stated that they had tried to quit smoking last year. Similarly, $44.8 \%$ of smokers made an attempt to quit in the past year, in $2010 .{ }^{3}$ Although more than half of the current smokers had tried to stop smoking, most of them did not receive any help or advice. One of the reasons may be unmet need, there are very limited health care service related to tobacco quit in Turkey. For examples, drugs used in quitting tobacco are not covered by the social insurance, counselling is not nationwide.

More than half of the current smokers stated that they want to stop. Similarly, in 2010, 53.0\% of current cigarette smokers stated they were interested in quitting. ${ }^{3}$ In India, over $76.0 \%$ of current cigarette smokers tried to stop smoking cigarettes in past year. ${ }^{11}$ In Shangai Medical University, 36.7\% of smokers had made at least one serious attempt to quit smoking in 1995. ${ }^{12}$

These studies show that most of students were trying to stop tobacco. If it is provided appropriate services, success rate is going to increase.

Motivation is very important in terms of success of clinical interventions in smoking cessation. It is clear that therapies can only work for smokers who are motivated to stop. A study carried out in a medical faculty reported that $64.4 \%$ of the current smokers declared that they wanted to quit. ${ }^{13}$ Mayda et al. found out that $65.6 \%$ of the current smokers had wanted to quit smoking. ${ }^{14}$ In the India GHPSS over $71 \%$ of current cigarette smokers and $73 \%$ of current users of other tobacco products wanted to quit tobacco. ${ }^{11}$ In this study nearly half of the smokers wanted to stop smoking. The desire to quit is lower among the current other tobacco user than the cigarette smokers. Although more than half of the current smokers had a desire to stop smoking, one in three of the other tobacco users did. The difference may be as a result of misconception that other tobacco forms are less harmful then cigarette.

Professional support increases success rate in smoking 
cessation. Jepson ${ }^{15}$ reported that physician advice or individual counselling, and workplace- and school-based activities were effective regarding to health behaviours.

However, professional support is not widespread. Nearly 1 in 6 quit attempts had received help or advice to stop smoking. More than half of the current cigarette smokers tried to stop smoking, but they failed. Despite to this failure, half of them want to stop still. Professional support such as counselling and drug therapies can help these groups.

The time-to-first-cigarette is a good single-item measure of nicotine dependence. Nearly half of the current users smoked their first cigarette within the first hour in the morning. In the GATS report, overall, $41.1 \%$ of daily smokers smoked tobacco within 30 minutes of awakening $-12.8 \%$ within 5 minutes after awakening. Men were more likely than women to have their first cigarette within 30 minutes after awakening. ${ }^{3}$ In a study carried out in physician and medical students, 20.6\% smoked their first cigarette within the first hour after awakening. ${ }^{16}$ These studies indicate a significant amount of the current smokers have a nicotine dependency.

Over $90 \%$ of the students thought that health professionals served as a role model for their patients and public in general. In another study, $43.0 \%$ of medical students thought that physicians had a role regarding to stop smoking in population. ${ }^{14}$ The results are similar to other studies from different countries. GHPSS, 2005-7 showed that majority of health professional students recognised that they are role models in society. ${ }^{17}$ In India, $96.9 \%$ of the students believed that health professionals had a role in giving advice or information on smoking cessation to patients. ${ }^{11}$ It can be seen that most of the students were aware of their role.

Over $90.0 \%$ of the students supported specific training on cessation techniques. Studies from many countries indicated that majority of medical students believed that they should receive training on counselling patients to quit using tobacco. ${ }^{17}$ In Italy, $87.7 \%$ of students believed that health professionals should receive specific training in techniques to quit smoking. ${ }^{18}$ In India GHPSS $91.0 \%$ of students expressed that health professionals should get specific training on cessation techniques. ${ }^{11}$

Most of the students said that they were taught in any of their classes about harmful effects of smoking. However, only half of them had discussed reasons why people smoke. Nearly all of the students had learned about the necessity to record tobacco use as a part of medical patient's history. In a study from Berlin, only one third of the students indicated that they felt qualified to council patients about tobacco depending, and that $51.2 \%$ of the students gave an advice to smokers about quitting. ${ }^{19}$ GHPSS $2005-7$ found out that in 73 of 80 sites, less than $40 \%$ of the students reported they received such training. ${ }^{17}$ The data of India GHPSS indicated a general lack of training by health professionals in patient cessation counselling techniques. ${ }^{11}$

Our findings show that most of the students learned something about smoking in their schools. The high prevalence of smoking indicates that these are not efficient or enough. Most of the students are willingness to take specific formal training on smoking related issues. Medical curriculum needs to be improved regarding to standardised education in terms of tobacco cessation techniques.

Comprehensive programs for tobacco control are essential to reduce prevalence of tobacco use. Cornuz ${ }^{20}$ implied that physician counselling and pharmacotherapeutic interventions for smoking cessation were among the most cost-effective clinical interventions. Keiding ${ }^{21}$ suggested that smoking cessation therapies were among the most cost-effective preventive healthcare measures. These studies show that drug therapies should be one of the main components of these programs. Treatment with varenicline for smoking cessation is cost-effective compared with nortriptyline and unaided cessation and even cost-saving compared with bupropion and nicotine replacement therapy. ${ }^{22}$ Annemanset al. concluded that varenicline was a cost-effective alternative to brief counselling and unaided cessation, and was a costsaving treatment in comparison with bupropion and nicotine replacement therapy, in a Belgian population of smokers willing to quit. ${ }^{23}$

Nicotine replacement therapy is well known among the students. Anti-depressant and varenicline are less known compared to nicotine replacement therapy. Therefore, varenicline deserves more attention of the medical students in Turkey.

\section{CONCLUSIONS}

More than half of the current smokers had tried to quit smoking last year, and overwhelming majority had taken no help or advice. Majority of students believe that health professionals have a role in giving advice or information on smoking cessation. Most of the students learned something about smoking in their schools, but these are not efficient or enough. Most of the students are ready to take specific formal training on smoking related issues and medical curriculums, and health care services in Turkey need to be revised regarding to

tobacco cessation. 
Turhan et al. Smoking Cessation and Attitudes, Belief, Observation, and Education of Medical Students, in Turkey

\begin{tabular}{|c|c|c|c|c|}
\hline Questions & Total & & $\begin{array}{l}\text { \% of "Yes" } \\
\text { answer }\end{array}$ & $95 \% \mathrm{Cl}$ \\
\hline \multirow{2}{*}{$\begin{array}{l}\text { How soon after you awake do you smoke your } \\
\text { first cigarette? }\end{array}$} & Within 30 minutes & 140 & 30.5 & $19.5-44.4$ \\
\hline & Within an hour & 140 & 44.9 & $22.8-69.1$ \\
\hline Do you want to stop smoking cigarettes now? & Cigarette smokers & 151 & 56.2 & $45.2-66.7$ \\
\hline $\begin{array}{l}\text { Do you want to stop using chewing tobacco, } \\
\text { snuff, bidis, cigars or pipes now? }\end{array}$ & Other tobacco users & 45 & 30.8 & $18.5-46.6$ \\
\hline $\begin{array}{l}\text { During the past year, have you ever tried to } \\
\text { stop smoking cigarettes? }\end{array}$ & Cigarette smokers & 174 & 60.4 & $53.7-66.8$ \\
\hline $\begin{array}{l}\text { Have you ever received help or advice to help } \\
\text { you stop smoking cigarettes? }\end{array}$ & Cigarette smokers & 198 & 16.4 & $9.2-27.6$ \\
\hline
\end{tabular}

Table 2. Opinions of the students on the specific training for health professionals, GHPSS- 2010, Turkey.

\section{Questions}

Should health professionals get specific training on cessation techniques? $n=1205$

Males

Females

Should health professionals get specific training on cessation techniques? $n=1211$

Current cigarette smokers

Current any tobacco users

Current other tobacco users besides cigarettes

Never other tobacco users besides cigarettes

Never cigarette smokers

Never any tobacco users

Total

$\begin{array}{lll}\text { Total } & \begin{array}{l}\text { \% of "Yes" } \\ \text { answer }\end{array} & 95 \% \mathrm{Cl} \\ & & \\ 575 & 88.7 & 81.4-93.4 \\ 630 & 93.1 & 89.2-95.7\end{array}$

\begin{tabular}{lll}
231 & 81.3 & $73.1-87.4$ \\
346 & 84.6 & $78.1-89.5$ \\
229 & 87.1 & $77.7-92.8$ \\
552 & 94.4 & $88.9-97.2$ \\
521 & 95.3 & $91.4-97.5$ \\
378 & 95.4 & $90.1-97.9$ \\
1115 & 92.1 & $86.7-94.2$ \\
\hline
\end{tabular}

Table 3. Opinions of the students on health professionals role and advise to stop smoking, GHPSS-2010, Turkey.

\begin{tabular}{|c|c|c|c|}
\hline Questions & $\mathbf{n}$ & $\begin{array}{l}\text { \% of "Yes" } \\
\text { answer }\end{array}$ & $95 \% \mathrm{Cl}$ \\
\hline \multicolumn{4}{|c|}{$\begin{array}{l}\text { Do health professionals serve as "role models" for their patients and the } \\
\text { public? }\end{array}$} \\
\hline Current cigarette smokers & 232 & 77.5 & $69.5-83.8$ \\
\hline Current any tobacco users & 347 & 79.6 & $72.5-85.2$ \\
\hline Current other tobacco users besides cigarettes & 230 & 81.0 & $75.5-85.5$ \\
\hline Never cigarette smokers & 520 & 96.4 & $94.3-97.7$ \\
\hline Never other tobacco users besides cigarettes & 551 & 96.7 & $94.9-97.9$ \\
\hline Never any tobacco users & 377 & 97.8 & $95.8-98.9$ \\
\hline Total & 1209 & 92.1 & 89.4-93.6 \\
\hline \multicolumn{4}{|c|}{$\begin{array}{l}\text { Should health professionals routinely advise their patients who smoke to } \\
\text { quit smoking? }\end{array}$} \\
\hline Current cigarette smokers & 232 & 78.7 & $64.2-88.4$ \\
\hline Current any tobacco users & 348 & 80.3 & $66.8-89.2$ \\
\hline Current other tobacco users besides cigarettes & 231 & 83.6 & $76.7-88.7$ \\
\hline Never other tobacco users besides cigarettes & 551 & 96.2 & $93.0-98.0$ \\
\hline Never cigarette smokers & 529 & 96.4 & $93.1-98.2$ \\
\hline Never any tobacco users & 377 & 97.1 & 89.4-99.2 \\
\hline
\end{tabular}


Total

Should health professionals routinely advise their patients who use other tobacco products to quit using these products?

Current cigarette smokers

Current any tobacco users

Current other tobacco users besides cigarettes

Never other tobacco users besides cigarettes

Never cigarette smokers

Never any tobacco users

Total

Do health professionals have a role in giving advice or information about smoking cessation to patients?

Current cigarette smokers

Current any tobacco users

Current other tobacco users besides cigarettes

Never other tobacco users besides cigarettes

Never any tobacco users

Never cigarette smokers

Total

Are a patient's chances of quitting smoking increased if a health profes-

sional advises him or her to quit?

Current cigarette smokers

Current other tobacco users besides cigarettes

Current any tobacco users

Never other tobacco users besides cigarettes

Never cigarette smokers

Never any tobacco users

Total

Are health professionals who smoke less likely to advise patients to stop

smoking?

Current other tobacco users

Current cigarette smokers

Current any tobacco users

Never cigarette smokers

Never any tobacco users

Never other tobacco users

Total

Are health professionals who use other tobacco products less likely to ad-

vise patients to stop smoking?

Current cigarette smokers

Current other tobacco users

Current any tobacco users

Never cigarette smokers

Total
121193.3

82.9-95.2

$229 \quad 79.4$

62.7-89.8

$345 \quad 80.5$

$229 \quad 82.3$

$549 \quad 96.2$

51896.3

$376 \quad 97.6$

$1207 \quad 92.6$

66.7-89.5

75.5-87.5

93.5-97.8

92.8-98.1

93.7-98.3

82.7-95.1

$231 \quad 87.1$

69.3-95.3

$347 \quad 89.3$

$230 \quad 93.3$

$550 \quad 97.9$

$337 \quad 98.6$

$519 \quad 98.8$

120994.4

78.7-95.0

87.3-96.5

95.9-99.0

96.3-99.5

97.1-99.5

92.5-97.1

$228 \quad 85.4$

72.8-92.7

$226 \quad 85.5$

77.0-90.9

34286.0

75.8-92.3

$548 \quad 91.7$

88.4-94.2

$518 \quad 93.8$

88.9-96.7

$376 \quad 94.4$

88.7-97.3

$1203 \quad 89.9$

87.3-93.3

$227 \quad 48.3$

42. 6-54.0

$228 \quad 48.7$

37.4-60.1

$342 \quad 49.4$

46.8-51.9

$521 \quad 63.5$

53.8-72.3

$379 \quad 64.5$

50.4-76.4

$552 \quad 65.4$

54.8-74.6

$1204 \quad 60.8$

55.0-62.7

$228 \quad 45.9$

34.3-57.9

$228 \quad 47.7$

41.9-53.6

$343 \quad 48.4$

44.7-52.1

$519 \quad 64.4$

55.8-72.2

120360.8
55.7-62.6 
Table 4. Percentage of "Yes" answers to questions on curriculum and training, GHPSS- 2010, Turkey.

Questions

During your school training, were you taught in any of your classes about the dangers of smoking?

Total \% of "Yes"

response response

$95 \% \mathrm{Cl}$

During your school training, did you discuss in any of your classes the

reasons why people smoke?

During your school training, did you learn that it is to record tobacco

use history as part of a patient's general medical history?

During your school training, have you ever received any formal training

in smoking cessation approaches to use with patients?

$1195 \quad 87.2 \quad 81.5-91.3$

During your school training, did you learn that it is important to provide

educational materials to support smoking cessation to patients who

want to quit smoking?

Have you ever heard of nicotine replacement product therapies in tobacco cessation programs?

\begin{tabular}{|c|c|c|c|}
\hline Current cigarette smokers & 227 & 90.7 & $84.0-94.7$ \\
\hline Never other tobacco users & 552 & 91.1 & $84.5-95.1$ \\
\hline Current other tobacco users besides cigarettes & 225 & 91.4 & $84.5-95.4$ \\
\hline Current any tobacco users & 340 & 91.4 & $84.6-95.4$ \\
\hline Never any tobacco users & 378 & 91.6 & $87.1-91.6$ \\
\hline Never cigarette smokers & 518 & 92.2 & $88.4-94.8$ \\
\hline Total & 1203 & 91.5 & $86.1-95.0$ \\
\hline $\begin{array}{l}\text { Have you ever heard of using antidepressants in tobacco cessation pro- } \\
\text { grams (such as bupropion or Zyban)? }\end{array}$ & 1204 & 45.7 & \\
\hline $\begin{array}{l}\text { Have you ever heard of using varenicline (Champix) in tobacco cessa- } \\
\text { tion programs? }\end{array}$ & 1202 & 30.8 & \\
\hline
\end{tabular}

Have you ever heard of using antidepressants in tobacco cessation programs (such as bupropion or Zyban)?

Have you ever heard of using varenicline (Champix) in tobacco cessa-

tion programs?

\section{REFERENCES}

1. WHO Report on the Global Tobacco Epidemic, 2008: The MPOWER package. Geneva, World Health Organization, 2008.

2. Aslan D. Halk Sagligi ile ilgili Guncel Sorunlar ve Yaklasımlar. Ankara, Mart 2009.

3. Available at: URL:http://www.ato.org.tr/storage/ publications/books/middleCol/pdf/halk_sagligi.pdf

4. The Ministry of Health of Turkey, Global Adult Tobacco Survey, Turkey Report - 2010 Available at: URL:http:// www.havanikoru.org.tr/Docs_Tutun_Dumaninin Zararlari/KYTA_Kitap_Tr.pdf

5. Kasikci M, Unsal A. Coban GI, Avsar G. Smoking habits of the final grade students at Ataturk University in Erzurum, Turkey. Tur Toraks Der. 2008;9:93-8.

6. Calıskan D, Culha G, Sarısen O, Karpuzoglu S, Tuncbilek A. Smoking behavior among medical school students and staff in Ankara University School of Medicine. Journal of Ankara University Faculty of Medicine. 2005;58(3):124-31.
7. Marakoglu K, Kutlu R, Sahsivar S. The frequency of smoking, quitting and socio-demographic characteristics of physicians of a medical faculty. West Indian Med J. 2006;55 (3):160-4.

8. Aslan D, Bilir N, Ozcebe H. Smoking Status of the Health Professionals and Influencing Factors, Ministry of Health, CDC, WHO and HASUDER. Ankara, 2008.

9. World Health Organization, The Role of Health Professionals in Tobacco Control, 2005. ISBN 9241593202.

10. Turkish Medical Association, Graduate Medical Education Report, 2008.

11. Global Health Professional Student Survey Administrator Handbook 2009.

12. Sinha DN, Singh G, GuptaPC, Pednekar M, Warrn CW, Asma S, et al. Linking India Global Health Professions Student Survey data to the World Health Organization framework convention on tobacco control. Indian J Cancer. 2010;47(1):30-4. 
13. Lei $Z$, Jingheng $H$, Jianzhong L. Smoking among Shanghai medical students and the need for comprehensive intervention strategies. Health Promotion International. 1997;2(1):27-32

14. Ilhan F, Aksakal N, Ilhan MN, Aygun R. Gazi Universitesi Tip Fakultesi ogrencilerinin sigara icme durumu. TSK Koruyucu Hekimlik Bulteni. 2005:4(4):188-98.

15. Mayda AS, Tufan N, Bastas S. Duzce Tip Fakultesi ogrencilerinin sigara konusundaki tutumlari ve icme sikliklari. TSK Koruyucu Hekimlik Bulteni. 2007:6(5):364-70.

16. Jepson RG, Harris FM, Platt $S$, Tannahill C. The effectiveness of interventions to change six health behaviours: a review of reviews. BMC Public Health. 2010; 8;10(1):538.

17. Cetinkaya F, Biricik SS, Nacar M. Prevalance of smoking and attitudes of the physicians and medical students towards smoking. Erciyes Medical Journal. 2006;28(4):163-71.

18. Warren CW, Jones NR, Chauvin J, Peruga A; GTSS Collaborative Group. Tobacco use and cessation counselling: cross-country. Data from the Global Health Professions Student Survey (GHPSS), 2005-7. Tob Control. 2008;17(4):238-47.
19. Saulle $R$, Bontempi C, Baldo V, Boccia G, Bonaccorsi G, Brusaferro S, et al. GHPSS multicenter Italian survey: smoking prevalence, knowledge and attitudes, and tobacco cessation training among third-year medical students Tumori. 2013;99(1):17-22.

20. Kusma B, Quarcoo D, Vitzthum K, Welte T, Mache S, Meyer-Falcke A, et al. Berlin's medical students smoking habits knowledge about smoking and attitudes toward smoking cessation counseling. Journal of Occupational Medicine and Toxicology 2010;5:9.

21. Cornuz J. Smoking cessation interventions in clinical practice. Eur J Vasc Endovasc Surg. 2007;34(4):397-404.

22. Keiding H. Cost-effectiveness of varenicline for smoking cessation. Expert Rev Pharmacoecon Outcomes Res. 2009;9(3):215-21.

23. Hoogendoorn $M$, Welsing $\mathrm{P}$, Rutten-van Mölken MP. Cost-effectiveness of varenicline compared with bupropion, NRT, and nortriptyline for smoking cessation in the Netherlands. Curr Med Res Opin. 2008;24(1):51-61.

24. Annemans L, Nackaerts K, Bartsch P, Prignot J, Marbaix S. Cost effectiveness of varenicline in Belgium, compared with bupropion, nicotine replacement therapy, brief counselling and unaided smoking cessation: a BENESCO Markov cost-effectiveness analysis. Clin Drug Investig. 2009;29(10):655-65. 